\title{
The Effects of Hypoxic Acidemia on Left Ventricular End-Systolic Elastance in Fetal Sheep
}

\author{
REUVEN M. LEWINSKY, RICHARD S. SZWARC, LEE N. BENSON, AND J. W. KNOX RITCHIE \\ Department of Obstetrics and Gynecology, Division of Perinatology, The Samuel Lunenfeld Research Institute, \\ Mount Sinai Hospital [R.M.L., J.W.K.R.]; and Division of Pediatric Cardiology, The Hospital for Sick Children \\ [R.S.S., L.N.B.], University of Toronto, Toronto, Canada
}

\begin{abstract}
Using the conductance catheter technique, we measured the effects of hypoxic acidemia on left ventricular end-systolic elastance in anesthetized, 133-d gestation, in utero fetal sheep $(n=7)$. Conductance and Millar catheters were introduced into the left ventricle through a carotid artery cutdown. Fetuses were rendered progressively hypoxic and acidemic by placental embolization with repeated injections of $5 \cdot 10^{5} 50-\mu \mathrm{m}$ plastic spheres every $15 \mathrm{~min}$ via a catheter placed in the fetal abdominal aorta. We recorded pressure-volume data and arterial blood gases at 15-min intervals. End-systolic elastance was computed using a single-beat method of extrapolating maximum isovolumic pressure. A mean of five boluses was required to cause fetal death. Placental embolization caused progressive fetal acidemia. Mean baseline fetal arterial $\mathrm{pH}$ was $7.32 \pm 0.06$ (mean \pm SD) and gradually decreased with embolization $(p<0.0001)$. A linear relationship was found to exist between elastance and $\mathrm{pH}$ with a mean decrease of $0.46 \mathrm{kPa} / \mathrm{mL}$ per 0.1 -unit drop in $\mathrm{pH}(r=0.96 ; p<$ $0.0001)$. Despite the decrease in end-systolic elastance, stroke volume and left-ventricular output were maintained due to a parallel decrease in afterload. The decrease in end-systolic elastance was gradual and extended over the entire clinically important range of $\mathrm{pH}$, rather than being a terminal event. This study, which, to our knowledge, is the first to use the conductance catheter to measure fetal left ventricular function demonstrates that hypoxic acidemia adversely affects myocardial contractility assessed by end-systolic elastance. (Pediatr Res 34: 38-43, 1993)
\end{abstract}

\section{Abbreviations}

IVC, inferior vena cava

SVC, superior vena cava

ESPVR, end-systolic pressure-volume relationship

$E_{e s}$, elastance at end systole (slope of ESPVR)

$L V$, left ventricle (left ventricular)

$\mathrm{dP} / \mathrm{dt}_{\max }$, the maximum of the first time derivative of the ventricular pressure wave form

$P_{\max }$, peak-developed $L V$ pressure at end-diastolic volume

Human uteroplacental insufficiency, a known cause of fetal hypoxic acidemia, may lead to the birth of asphyxiated newborns. Electronic fetal heart rate monitoring is the standard method of

Received July 3, 1991; accepted February 10, 1993.

Correspondence and reprint requests: R. M. Lewinsky M.D., Department of Perinatology, Mount Sinai Hospital, Room 775, 600 University Ave., Toronto, Ontario M5G 1X5, Canada. assessing fetal status during labor. The diagnosis of fetal compromise is based upon the recognition of different fetal heart rate patterns, several of which are nonspecific and often lead to the overdiagnosis of fetal distress. Our aim, as clinicians, is to correctly identify those cases in which hypoxic acidemia is the underlying cause for the heart rate changes. Metabolic acidemia and changes in intracellular $\mathrm{pH}$ have been shown to affect myocardial function (1). Indices of cardiac function with the potential to reflect fetal distress more accurately should therefore be investigated.

The present study was devised to examine the effects of hypoxic acidemia on myocardial function in in utero fetal sheep. The conductance catheter technique, which has little effect on cardiac mechanics, was used to measure fetal LV volume. $\mathrm{E}_{\mathrm{es}}$, the slope of the ESPVR, was measured to assess ventricular contractility. It is a relatively load- and heart rate-insensitive measure of the intrinsic contractile properties of the myocardium $(2,3)$. This technique has previously been used in the human adult as well as in numerous animal models and age groups (46 ), but this, to our knowledge, is the first application in the fetus. Other more traditional indices of cardiac performance were also correlated with the deteriorating fetal acid-base status induced by progressive placental embolization.

\section{MATERIALS AND METHODS}

Surgical procedure. Surgery was performed on seven pregnant ewes with a singleton gestation between 132 and 134 d. Anesthesia was induced with i.v. thiopental sodium and maintained by positive-pressure ventilation with 1 to $1.5 \%$ isoflurane and oxygen. The ewes were mildly hyperventilated to prevent $\mathrm{CO}_{2}$ accumulation. The fetal head and neck were withdrawn through a uterine incision. A $2 \mathrm{~F}$ catheter-tip pressure transducer (Millar, Houston, TX) was introduced through the left carotid artery, advanced into the $\mathrm{LV}$, and positioned such that no impact artifact was evident. A $4 \mathrm{~F}$, eight-electrode conductance catheter (made in-house) was similarly advanced through the same carotid artery and positioned in the LV such that its distal electrode was at the apex and the most proximal electrode cephalad to the aortic valve. Correct placement of the conductance catheter in the LV was determined by monitoring the segmental volume phase relationships and counterclockwise pressure-volume loop formation. The conductance catheter outer electrode spacing was $4 \mathrm{~cm}$, the appropriate length being established from LV longaxis measurements previously made on fetuses of the same gestational age. Correct catheter electrode spacing and position were also confirmed at necropsy. A venous line was advanced through the left jugular vein to the right atrium. The fetus was replaced and the uterine incision closed. The hind part of the fetus was then withdrawn through a separate uterine incision, and a fluid-filled catheter was introduced via a femoral artery 
and advanced $10 \mathrm{~cm}$ to a position immediately above the abdominal aortic trifurcation. A Fogarty balloon catheter (Baxter, McGaw Park, IL) was introduced through a femoral vein and advanced $18 \mathrm{~cm}$ such that the balloon was located in the IVC between the diaphragm and right atrium. Occlusion of the fetal IVC at this level (i.e. above the insertion of the ductus venosus) assures a profound reduction upon venous return. In one animal, an additional balloon catheter was also introduced through the left jugular vein to a position in the SVC proximal to the right atrium. The intravascular distance of the femoral catheters was previously established in fetuses of the same gestational age and verified at necropsy. The hind part of the fetus was then replaced and the uterine incision closed. The catheters were exteriorized through the ewe's abdominal incision, which was held closed with clamps. A vascular catheter was placed in the femoral artery of the ewe to monitor maternal blood pressure and gases.

Study protocol. Fetal hypoxic acidemia was gradually induced by embolizing the placenta with injections of $5 \cdot 10^{5} 50-\mu \mathrm{m}$ polyethylene microspheres $(3 \mathrm{M}, \mathrm{St}$. Paul, $\mathrm{MN})$, repeated at 15 min intervals until fetal death occurred. Instantaneous LV pressure-volume loops were monitored and digitally recorded at baseline and before each embolization. Data were acquired at steady state as well as during IVC occlusion. The occlusions were performed by gradually inflating the caval balloon with $0.75 \mathrm{~mL}$ of saline over a period of 6 to $8 \mathrm{~s}$. Three IVC occlusions were performed at each level of embolization, full recovery between which was confirmed by return to preocclusion heart rate and LV pressures and volumes. In addition, the effect of SVC occlusion was compared with IVC occlusion in one animal. After hemodynamic recordings, fetal arterial blood samples $(0.4 \mathrm{~mL})$ were obtained and immediately analyzed for gas tensions and $\mathrm{pH}$ using a blood gas analyzer (model 170, Corning Medical, Medfield, MA) and temperature corrected to $39^{\circ} \mathrm{C}$. Because acidosis affects the electrical resistance of blood, this parameter was also determined at each interval using a 4-mL cuvette connected to a modified Sigma-5 signal conditioner (Leycom, Oesgstgeest, The Netherlands). This blood was returned to the fetus.

Data acquisition and analysis. The principles and technique of the conductance catheter method of $\mathrm{LV}$ volume estimation are described in detail elsewhere (4-7). Briefly, the conductance catheter was connected to the Sigma-5 unit, which applied an excitation current $(30 \mu \mathrm{A}, 20 \mathrm{kHz})$ to the outer electrodes and measured the five segmental conductances, $G_{i}$, between intervening electrode pairs. Total time-varying conductance, $G(t)$, was estimated as the algebraic sum:

$$
G(t)=\sum_{i=1}^{5} G_{i}+\frac{G_{1}}{3}
$$

where $1 / 3$ term approximates the conductance of blood within the conic apical region not actually being measured by the catheter. The instantaneous $\mathrm{LV}$ volume, $\mathrm{V}(\mathrm{t})$, is then obtained by:

$$
V(t)=\frac{1}{\alpha}\left(L^{2} \cdot \rho \cdot G(t)-\alpha V_{c}\right)
$$

where $\alpha$ is a unitless, empirical coefficient relating conductance catheter-derived stroke volume to that obtained by some other method (i.e. "gold standard"). In this study, $\alpha$ was assumed to be $1 . \mathrm{L}$ is the interelectrode spacing, and $\rho$ is the specific electrical resistance of blood as measured with the rho cuvette. The parallel conductance volume, $\mathrm{V}_{\mathrm{c}}$, is a correction term required to account for the conductivity of structures surrounding the LV blood pool. It was determined by the method of dilution (4), whereby the conductivity of blood was transiently altered by bolus injection of $0.5 \mathrm{~mL}$ of $3 \mathrm{M} \mathrm{NaCl}$ into the right atrium without affecting systolic pressure. LV pressure, five segmental conductances, and ECG were digitized $(250 \mathrm{~Hz}, 12 \mathrm{bit})$ by an IBM AT compatible microcomputer and stored on hard disk for subsequent analysis using software developed at The Toronto Hospital for Sick Children.

$\mathrm{E}_{\mathrm{es}}$ was computed by two methods. The first of these used transient balloon occlusion of the IVC to modulate preload. This generated a family of pressure-volume loops over a range of loading conditions (Fig. 1). Linear regression of the end-systolic pressure-volume coordinates (maximal ratio of pressure to volume), yielded a first approximation of the ESPVR and an initial volume intercept $V_{0}$, the unstressed ventricular volume. $E_{e s}$ was then computed using the time-varying model (8):

$$
E(t)=\frac{P(t)}{V(t)-V_{0}(t)}
$$

This yielded a new estimate of $V_{0}$, which was subsequently used in recomputing $\mathrm{E}_{\text {es. }}$. The iterations were repeated until the difference between the new value for $V_{0}$ and its previous value was $<0.1 \mathrm{~mL}$.

The second method of computing $E_{e s}$ was by analysis of pressure-volume loops under steady state loading conditions. Knowing the $P_{\max }$ of an isovolumic (nonejecting) contraction at end-diastolic volume $\left(V_{e d}\right)$ can allow determination of $E_{e s}$ from a single cardiac cycle. If the ESPVR of an ejecting ventricle is equivalent to that generated by the same ventricle beating isovolumically, $\mathrm{E}_{\mathrm{es}}$ will be the slope of the line connecting the endsystolic pressure-volume coordinate and the $P_{\max }-V_{\text {ed }}$ point (Fig. 2), or

$$
E_{e s}=\frac{P_{\max }-P_{e s}}{V_{e d}-V_{e s}}
$$

The pressure wave form of an isovolumic LV beat has previously been shown to follow a sinusoidal trajectory $(9,10)$. Ejecting and isovolumic beats are identical from the onset of contraction to the time of $\mathrm{dP} / \mathrm{dt}_{\max }$, which normally occurs before the opening of the aortic valve (Fig. 3). Although the duration, or period (T), of an isovolumic beat (i.e. the time from onset of contraction to the end of active relaxation) is typically longer than that of an ejecting beat, the contraction phases of both beats are of similar length. Based on these observations, a mathematical model was developed to predict $P_{\max }$. As the isovolumic pressure can be described by a sine, its angular derivative corresponds to a cosine of the same amplitude. Thus, the amplitude of $\mathrm{dP} / \mathrm{d} \Theta$, which is simply $\mathrm{dP} / \mathrm{dt}(\mathrm{kPa} / \mathrm{mL})$ converted to angular units $(\mathrm{kPa} / \mathrm{radian})$, is equivalent to that of the isovolumic pressure wave form. This identity is applied to estimate $P_{\max }$ from the pressure data of an ejecting beat by:

$$
P_{\max }=\frac{d P / d t_{\max } \cdot T}{2 \pi}+P_{d c}
$$

where $P_{d c}$ is the vertical offset of the pressure wave form, the pressure at which $\mathrm{dP} / \mathrm{dt}_{\max }$ occurs. The period of the extrapolated, nonejecting cycle is known because the time from $\mathrm{dP} / \mathrm{dt}_{\max }$ to

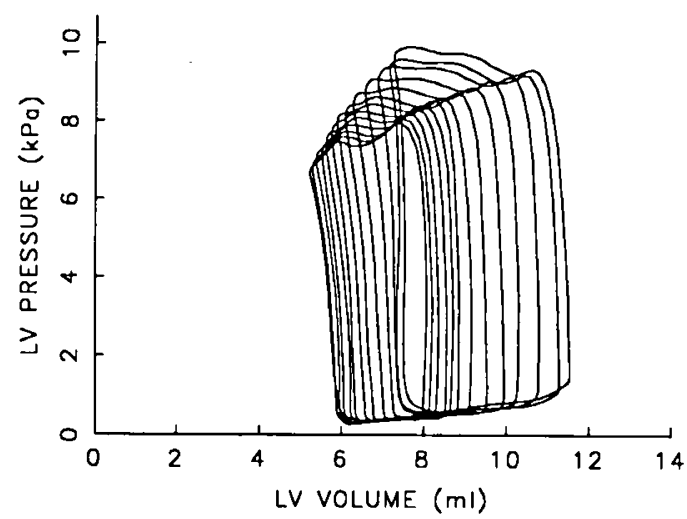

Fig. 1. Fetal LV pressure-volume loops obtained during an IVC occlusion. 


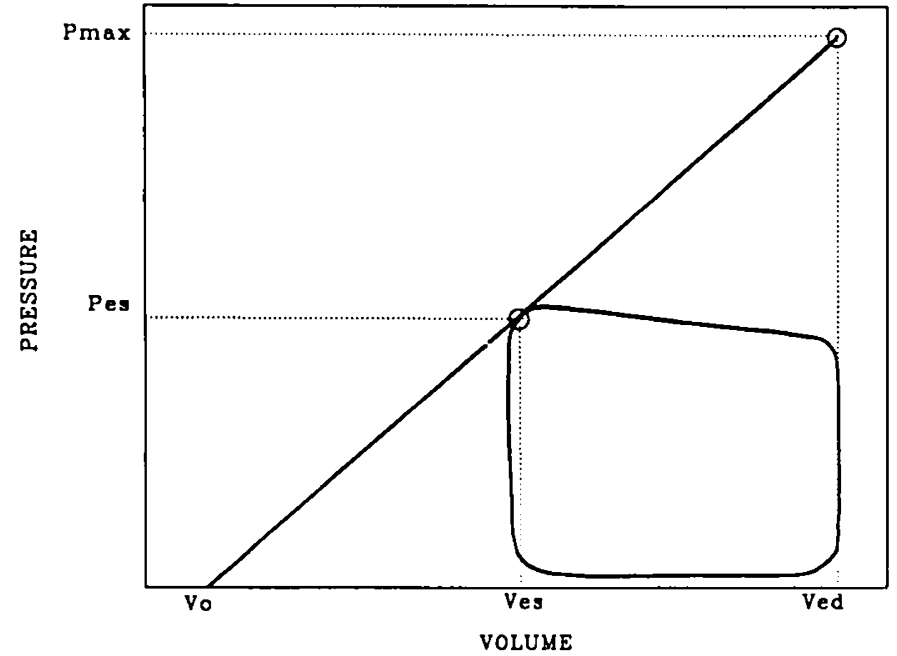

Fig. 2. Schematic diagram illustrating how the ESPVR is determined from a single cardiac cycle. P max is the extrapolated peak isovolumic pressure developed at end-diastolic volume $(\mathrm{Ved})$. $\mathrm{E}_{\mathrm{es}}$ is the slope of the line joining that point with the end-systolic pressure-volume coordinate (Pes, Ves); Vo is the volume axis intercept or the unstressed ventricular volume.

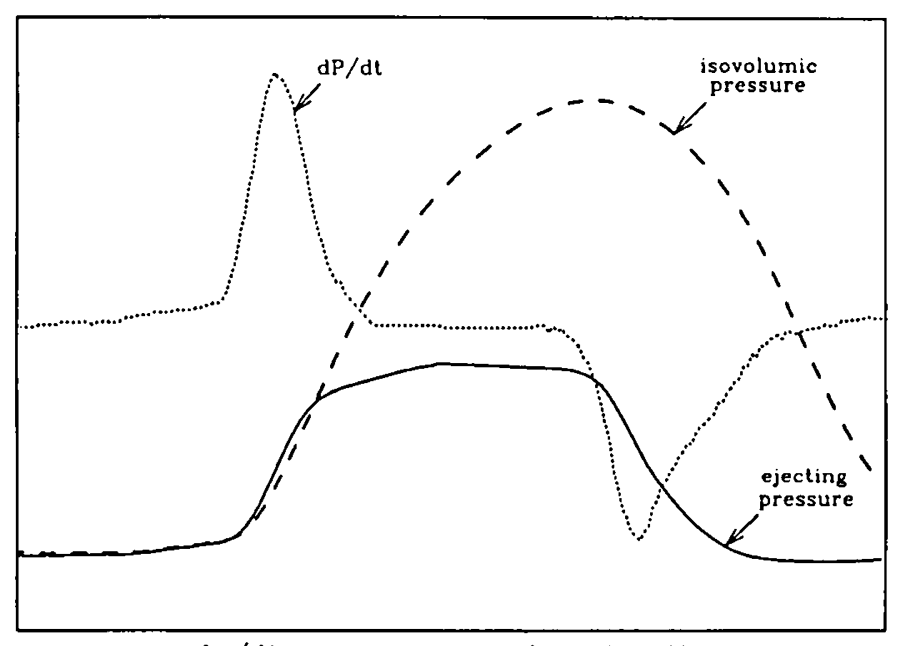

$\mathrm{dp} / \mathrm{dt} \max$

end contraction

Fig. 3. Temporal representation of the ejecting pressure, $\mathrm{dP} / \mathrm{dt}$, and the corresponding isovolumic pressure of a single cardiac cycle. Ejecting and isovolumic pressures are similar during the initial phase of contraction. The end of contraction of both beats essentially coincide.

the end of contraction is the same in both ejecting and isovolumic beats and occupies $1 / 4 \mathrm{~T}$ of the isovolumic cycle. We tested this method in experiments in which the intact hearts of eight pigs were made to beat isovolumically by sudden tightening of a snare around the aorta. A linear relationship $(n=16$, slope 1.08, $r=$ 0.96 ) was found to exist between the observed peak isovolumic pressure and that predicted from ejecting beats (10).

LV stroke volume and heart rate were measured, and LV output was computed for the baseline state and before each bolus injection. In addition, $\mathrm{dP} / \mathrm{dt}_{\max }$ was measured at each state and normalized to the baseline heart rate. Afterload was assessed by measuring arterial elastance, the ratio of end-systolic pressure to stroke volume $(11,12)$.

Each value given represents an average of 20 consecutive cardiac cycle measurements, taken immediately preceding each microsphere bolus injection.

Statistical analysis. Analysis of variance with repeated measures was used to determine the significance of changes in blood gas values with placental embolization. The relationships be- tween hemodynamic indices and $\mathrm{pH}$ were determined by multiple regression analysis, with dummy variables using effects coding. This approach takes into account the wide interanimal variability of values, such that only within-fetus differences are considered in the statistical analysis (13). As an estimate of between-fetus variability of each hemodynamic parameter, the mean and SD of the dummy variable coefficients were computed. Significance was assumed at the $p<0.05$ level.

This study was approved by the hospital animal care committee following the guidelines of the Canadian Council for Animal Care.

\section{RESULTS}

A mean of five (range four to six) microsphere boluses were required to cause fetal death. Placental embolization caused progressive fetal asphyxia (Fig. 4). Mean baseline fetal arterial $\mathrm{pH}$ was $7.32 \pm 0.06$ and progressively decreased with embolization $(p<0.0001)$. The mean baseline $\mathrm{PCO}_{2}$ was $7.01 \pm 1.78 \mathrm{kPa}$, gradually increasing with embolization $(p=0.01)$. The mean baseline $\mathrm{Po}_{2}$ was $2.73 \pm 0.37 \mathrm{kPa}$ and progressively decreased with embolization $(p<0.01)$.

The results of multiple linear regression analyses relating the individual hemodynamic parameters to $\mathrm{pH}$ are summarized in Table 1. Baseline heart rate was $180 \pm 35$ beats per min, LV stroke volume was $2.74 \pm 1.04 \mathrm{~mL}$, and $\mathrm{LV}$ output was $441.1 \pm$ $219.6 \mathrm{~mL} / \mathrm{min}$. These values did not change with placental embolization. End-systolic pressure, and therefore afterload, as measured by arterial elastance (Fig. 5), decreased significantly with $\mathrm{pH}$.

At each level of embolization, $E_{e s}$, as assessed by single-beat analysis, was reproducible when applied to 20 consecutive cardiac cycles with coefficients of variation ranging from 0.02 to 0.06 . $\mathrm{E}_{\text {es }}$ decreased significantly with $\mathrm{pH}$ (Fig. 6). The drop in $\mathrm{pH}$ caused a decrease in $\mathrm{dP} / \mathrm{dt}_{\max }$ that was even greater and more significant when $\mathrm{dP} / \mathrm{dt}_{\max }$ was normalized for heart rate (Fig. 7).

Measurement of $E_{\text {es }}$ using the IVC occlusion technique yielded inconclusive results. Although highly linear ESPVR were obtained for each occlusion, $E_{\text {es }}$ could not be reliably determined, because values varied significantly between the three occlusions performed at each level of embolization. Although all IVC occlusions resulted in a decrease in end-diastolic volume, some pressure-volume loops exhibited a paradoxical increase in stroke volume (Fig. 8). It was, therefore, not possible to correlate this measure with $\mathrm{pH}$. In the one animal in which the SVC was occluded, values of $E_{e s}$ measured by the iterative method were found to be in line with those obtained by steady state analysis $(r=0.99$; coefficient of variation $=0.06)$.

Although the injection of hypertonic $\mathrm{NaCl}$ into the right atrium had an immediate effect of the LV volume signal, mixing was deemed adequate because all segments showed a simultaneous response lasting several beats. However, it is most likely that, of the saline injected into the right atrium, only a small fraction entered the LV through the foramen ovale. The remainder went to the right ventricle, thus altering the parallel conductance due to the right ventricular blood pool. For this reason, we elected not to include results based on absolute volume determinations in this study.

\section{DISCUSSION}

The conductance catheter method has become a well-established technique of measuring instantaneous LV volume in the intact adult heart. Recently, this method has been validated in newborn piglets (14), the size of which is comparable to that of near-term fetal sheep. Combining conductance catheter volumes with a simultaneous LV pressure facilitates the computation of $\mathrm{E}_{\mathrm{es}}$, a relatively load-independent index of contractility.

The conventional method of measuring $E_{\text {es }}$ requires preload modulation using IVC occlusions. Several mechanisms may 

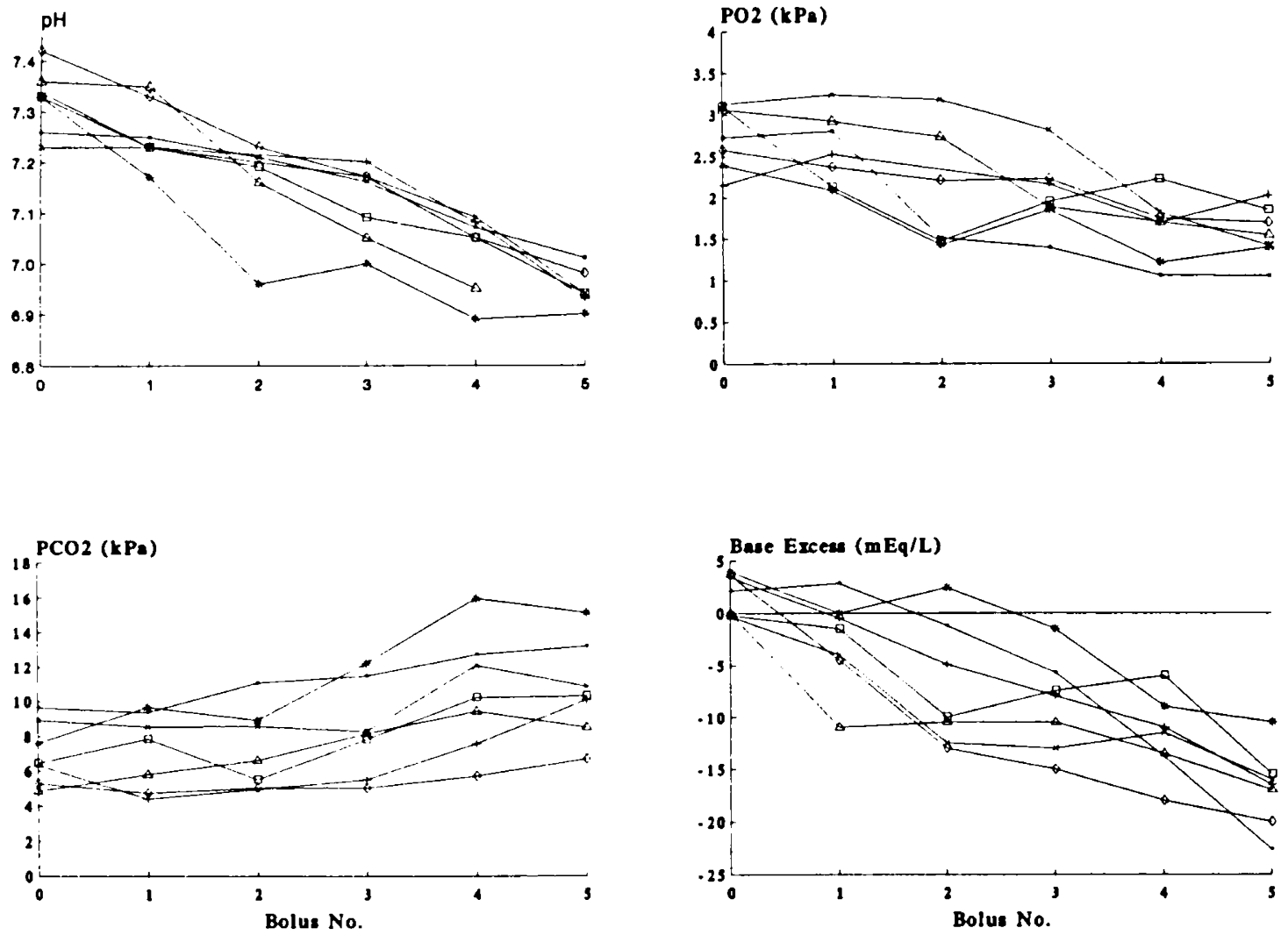

Fig. 4. Changes in blood gases that occurred with placental embolization in seven fetal sheep.

Table 1. Results of multiple linear regression analyses for hemodynamic variables*

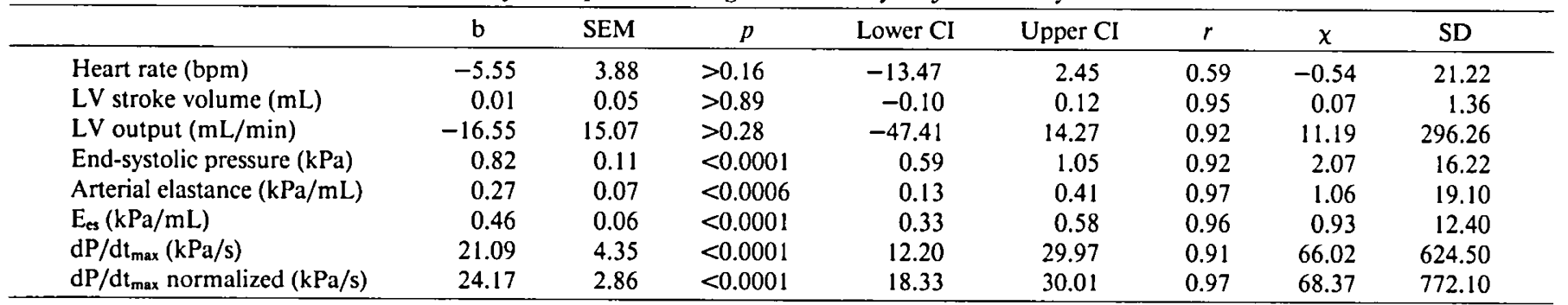

* All coefficients, $b$, the slopes of the relationship of each dependent variable to $\mathrm{pH}$, are given in their respective units per 0.1 unit change in pH. The $p$ values represent the significance of the effect of $\mathrm{pH}$ on the dependent variables. Lower and upper $\mathrm{CI}$ are the $95 \%$ confidence intervals. An estimate of the between-fetus variability is given by $\chi$ and SD of the six fetal coefficients.

underlie the nonrepeatability of measurements obtained by this method in our study. The observation that SVC occlusions yielded similar elastances to steady state analysis is most likely coincidental. In the absence of autonomic blockade, the variability in $E_{e s}$ may have resulted from reflex activation of baroreceptors and fluctuations in catecholamine levels. Another possible explanation may be provided by the unique ventricular interaction characteristic of the fetal heart. In the fetus, the dominant right ventricle operates at systemic pressures and provides about $2 / 3$ of the combined ventricular output. By decreasing venous return and right ventricular filling, septal compression of the LV space may be reduced. If this effect is not linearly correlated with the decrease in LV volume during IVC occlusions, the resulting pressure-volume relationships may be irregular. In addition, the proportion of blood passing through the foramen ovale may be variably affected by IVC occlusion, further confounding the LV ESPVR. It is also possible that the decrease in right ventricular volume during IVC occlusion is associated with a reduction in parallel conductance, which would be most pronounced at the end of ejection, thus causing underestimation of LV end-systolic volume. This may be the reason for the occasional atypical appearance of the pressure-volume loops during IVC occlusions (Fig. 8), in which stroke volume paradoxically appeared to be increasing during preload reduction. The relative contributions of these mechanisms to the error in determination of $L V E_{\text {es }}$ by IVC occlusion using the conductance catheter technique in fetal lambs remains to be determined.

Another method of measuring $E_{e s}$, which does not require load modulation, is gaining acceptance. Sunagawa et al. (9) introduced a technique of estimating $P_{\max }$ that exploits the sinusoidal behavior of isovolumic pressure wave forms. These investigators applied a nonlinear regression to fit the isovolumic contraction and relaxation phases of the pressure wave form of ejecting beats to a mathematical model describing a nonejecting beat. A good correlation between single-beat elastance using the method of Sunagawa $e t$ al. and that generated by IVC occlusion has been reported in dogs (15) and in humans (16). This formulation, however, is deficient because it ignores the asymmetry of the pressure wave form of the ejecting contractions. In addition, the abbreviation of ejecting relative to isovolumic beats was overlooked. The method used for the determination of $P_{\max }$ in the current study involves only the isovolumic contraction phase of the ejecting beat, the only segment that is identical to that of a nonejecting beat. The relaxation phase of an ejecting beat bears 


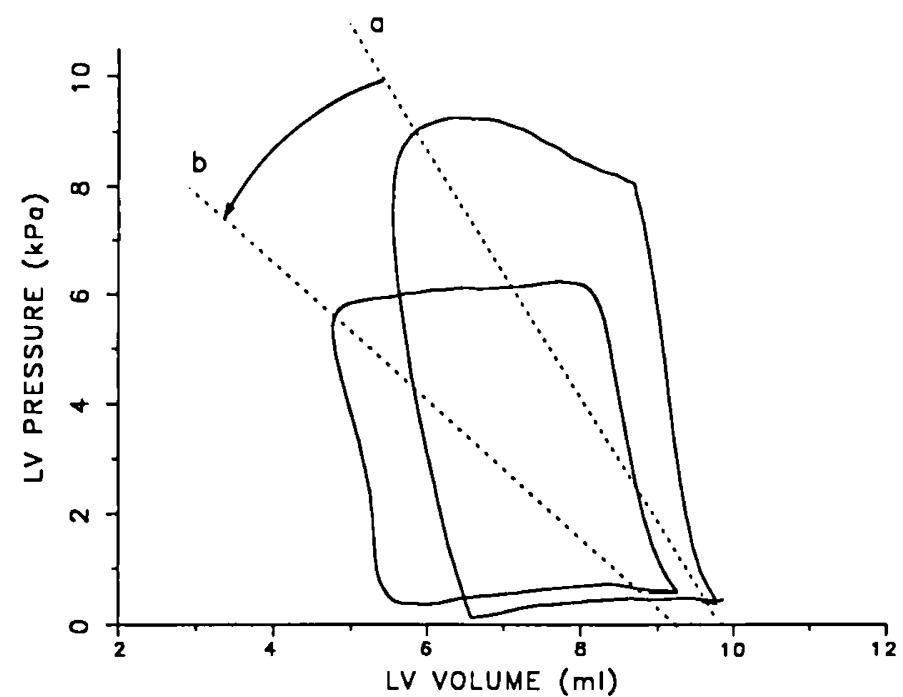

Fig. 5. Pressure-volume loops from one fetal sheep showing arterial elastance (the slope of the dotted lines) at baseline $(a)$ and before the 5 th placental embolization $(b)$. The reduction in afterload is depicted by the decreased arterial elastance.

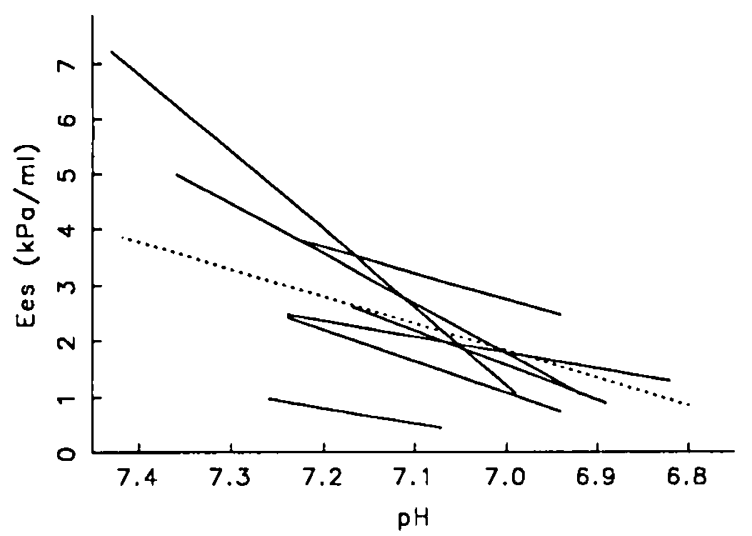

Fig. 6. Changes in fetal $\mathrm{LV}$ end-systolic elastance $\left(\mathrm{E}_{\mathrm{es}}\right)$, associated with the change in arterial $\mathrm{pH}$. Solid lines depict regression slopes for individual animals. The dotted line indicates the mean slope for seven animals.

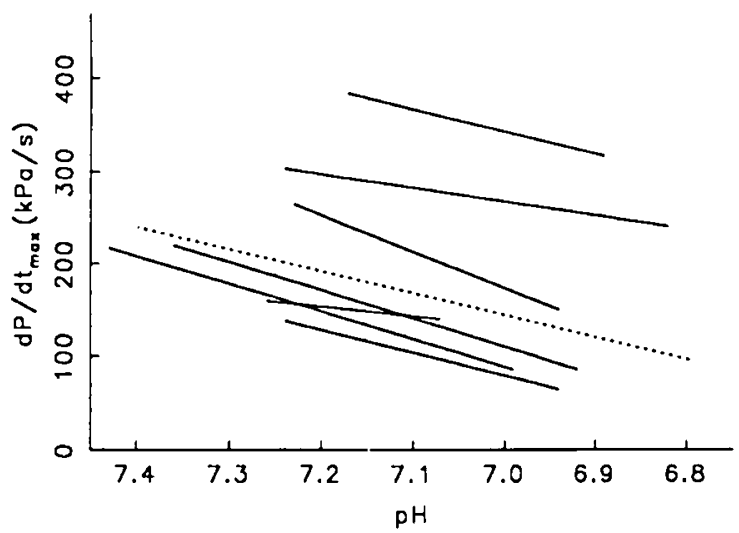

Fig. 7. Changes in fetal $\mathrm{LV} \mathrm{dP} / \mathrm{dt}_{\max }$, normalized for heart rate, associated with the change in arterial $\mathrm{pH}$. Solid lines depict regression slopes for individual animals. The dotted line indicates the mean slope for seven animals.

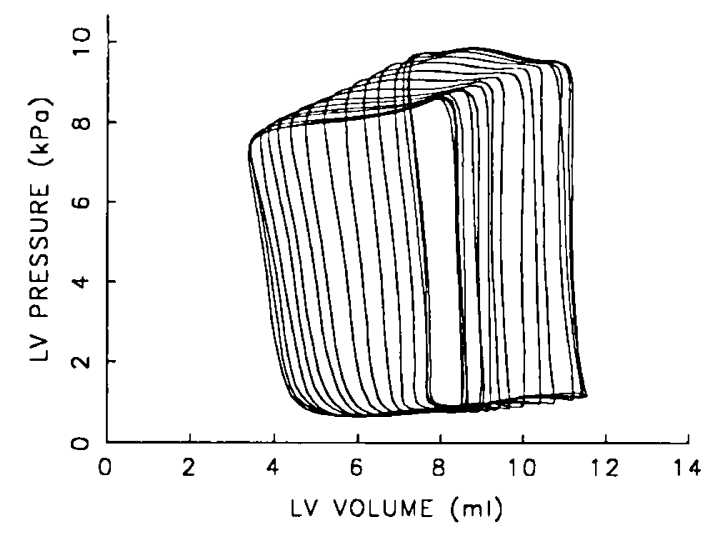

Fig. 8. Fetal LV pressure-volume loops obtained during an IVC occlusion, showing a paradoxical increase in stroke volume with decrease in preload.

little resemblance to that of an isovolumic beat. Although Sunagawa $e t$ al. defined the period of the isovolumic beat as the time from end-diastole to the time when pressure returns to that value, this does not take into consideration the higher amplitude and the slower relaxation rate of the isovolumic beat. Our method overcomes this underestimation of the period by not constraining it to that of the ejecting beat. In contrast to the IVC occlusion method, steady state analysis proved to be highly reproducible.

Another issue that merits attention when the conductance catheter technique is applied to the fetus relates to the measurement of parallel conductance. In the adult model, when the bolus injection of hypertonic $\mathrm{NaCl}$ is given, a delayed response in the LV conductance signal is usually observed due to the time required to pass through the pulmonary circulation. This delay, encompassing several beats, allows adequate mixing with blood. In the fetus, the foramen ovale allows almost immediate shunting of a portion of the saline from the right atrium to the left heart. This did not impede adequate mixing, as indicated by uniform segmental volume changes, which is required for proper determination of parallel conductance. The saline entering the right ventricle may, however, have introduced error in the determination of absolute volumes. Because of this possible limitation, absolute volumes were not considered in this study. In future studies, this limitation may be overcome by injecting the saline directly into the pulmonary artery through a Swan-Ganz catheter, although this could significantly complicate the instrumentation. The possibility of an alternative solution has arisen from observations made in a more recent study. After saline injection into the right atrium, the volume signal beyond the immediate response due to shunting through the foramen ovale was monitored. A second, delayed increase in the LV volume signal due to pulmonary venous return was observed (unpublished observations). This second response could be used to compute parallel conductance, thus avoiding the influence of saline on right ventricular conductivity.

There was a progressive decrease in LV contractility, as determined by $E_{e s}$, associated with deepening fetal hypoxic acidemia. This decrease in elastance was gradual and extended over the entire clinically important $\mathrm{pH}$ range, rather than being a terminal event. This is in agreement with findings of Teplinsky et al. (19), who studied the effect of lactic acidemia, and Walley et al. (20), who investigated the effects of respiratory acidosis on LV function in adult dogs. Both studies found that LV elastance decreased with $\mathrm{pH}$. Our findings in the intact heart are also in concordance with the observation that changes in intracellular $\mathrm{pH}$ adversely affect myocardial function (1).

In other studies, fetal hypoxemia with or without acidemia was created by interventions such as the induction of maternal hypoxemia, occlusion of the uterine or umbilical circulations, or the direct infusion of acid into the fetal circulation. Clinically, 
maternal hypoxemia is very uncommon as a cause for fetal asphyxia. Furthermore, fetal asphyxia is a gradually progressive condition, where acidemia is paralleled by tissue acidosis. The intravascular administration of acid is not accompanied by $\mathrm{CO}_{2}$ accumulation, and the degree of tissue acidosis generated by this intervention, especially myocardial tissue acidosis that affects contractility, might not accurately reflect clinical asphyxia. We have previously shown that embolization of the fetal placenta in sheep results in a gradually deepening hypoxic acidemia (21) and have thus decided to use this method in the current study.

When metabolic acidemia was induced by $\mathrm{HCl}$ infusion in unanesthetized newborn lambs, it caused a significant decrease in $\mathrm{LV} \mathrm{dP} / \mathrm{dt}_{\max }$ from $410.56 \pm 20.80 \mathrm{kPa} / \mathrm{s}$ at $\mathrm{pH} 7.42$ to 246.60 $\pm 25.1 \mathrm{kPa} / \mathrm{s}$ at $\mathrm{pH} 7.11$ (22). Similar findings were reported when lactic acidemia was induced in adult dogs: $\mathrm{LV} \mathrm{dP} / \mathrm{dt}_{\max }$ decreased from $270.73 \pm 91.40 \mathrm{kPa} / \mathrm{s}$ at $\mathrm{pH} 7.4$ to $228.20 \pm$ $68.50 \mathrm{kPa} / \mathrm{s}$ at $\mathrm{pH} 7.1$ (19). We found a similar decrease in LV $\mathrm{dP} / \mathrm{dt}_{\max }$. It should, however, be noted that $\mathrm{dP} / \mathrm{dt}_{\max }$ is not a pure measure of contractility because it is also influenced by factors such as heart rate and poreload. Isoflurane may have caused fetal myocardial depression; nevertheless, this anesthetic has only minimal cardiovascular effects in the adult and in the fetus when used in low concentrations, as in our study $(23,24)$, so we suspect this effect to be small.

When previously studied, hypoxemia was found not to affect fetal LV stroke volume $(25,26)$, which is in agreement with our observations. Our finding of a gradual reduction in afterload provides an explanation for the mechanism by which the LV is able to maintain its stroke volume despite a decrease in contractility. A decrease in afterload has previously been associated with acidosis in adult dogs (20). Once complicated by acidemia, combined $(25,26)$ or individual $(27)$ ventricular output in chronically instrumented fetal sheep decreases, mainly as a result of bradycardia. In this study, heart rate and LV output were maintained. This is in accordance with the previously described observation that, in acute experiments on fetal sheep, the bradycardic effect of hypoxia was negated by activation of aortic chemoreceptors (28).

In conclusion, this study, which used the conductance catheter technique for the assessment of fetal ESPVR, demonstrated tight coupling of fetal acid-base balance and LV contractility. Furthermore, the correlation between $\mathrm{pH}$ and $\mathrm{E}_{\text {es }}$ extended over the entire range of clinical importance. These observations suggest that indices of myocardial function should be explored as a means of improving upon the diagnostic accuracy currently provided by fetal heart rate monitoring.

\section{REFERENCES}

1. Jacobus WE, Pores IH, Taylor JG, Nunnally RL 1978 Tight coupling of intracellular $\mathrm{pH}$ and ventricular performance. Mol Cell Cardiol 10(suppl 1):39(abstr)

2. Kass D, Maughan WL, Mao Guo Z, Kono A, Sunagawa K, Sagawa K 1987 Comparative influence of load versus inotropic states on indexes of ventricular contractility: experimental and theoretical analysis based on pressurevolume relationships. Circulation 76:1422-1436

3. Sagawa K, Maughan WL, Suga H, Sunagawa K 1988 Cardiac Contraction and the Pressure-Volume Relationship. Oxford University Press, New York, pp $111-119$

4. Baan J, van der Velde ET, de Bruin HG, Smeenk GJ, Koops J, van Dijk AD, Temmerman D, Senden J, Buis B 1984 Continuous measurement of left ventricular volume in animals and humans by conductance catheter. Circulation 70:812-823

5. Burkhoff D, van der Velde ET, Kass D, Baan J, Maughan WL, Sagawa K 1985 Accuracy of volume measurement by conductance catheter in isolated, ejecting canine hearts. Circulation 72:440-447

6. Kass D, Yamazaki T, Burkhoff D, Maughan WL, Sagawa K 1986 Determination of left ventricular end-systolic pressure-volume relationships by the conductance (volume) catheter technique. Circulation 73:586-595

7. Baan J, Aouw Jong TT, Kerkhof PLM, Moene RJ, Van Dijk AD, Van der Velde ET, Koops J 1981 Continuous stroke volume and cardiac output from intra-ventricular dimensions obtained with impedance catheter. Cardiovasc Res 15:328-334

8. Baan J, van der Velde ET 1988 Sensitivity of left ventricular end-systolic pressure-volume relationships to type of loading intervention in dogs. Circ Res 62:1247-1258

9. Sunagawa K, Yamada A, Senda Y, Kikuchi Y, Nakamura M, Shibahara T, Nose Y 1980 Estimation of the hydromotive source pressure from ejecting beats of the left ventricle. IEEE Trans Biomed Eng 27:299-305

10. Szwarc RS, Cleveland D, Benson L 1992 Left-ventricular isovolumic developed pressure $\left(\mathrm{P}_{\max }\right)$ estimated from single ejecting contractions. Mol Cell Cardiol 24(suppl V):37(abstr)

11. Sunagawa K, Maughan WL, Burkhoff D, Sagawa K 1983 Left ventricular interaction with arterial load studied in isolated canine ventricle. Am J Physiol 245:H773-H780

12. Kass D, Grayson R, Marino P 1990 Pressure-volume analysis as a method for quantifying simultaneous drug (Amrinone) effects on arterial load and contractile state in vivo. J Am Coll Cardiol 16:726-732

13. Glantz SA, Slinker BK 1990 Primer of applied regression and analysis of variance. McGraw-Hill, New York, pp 381-390

14. Teitel DF, Klautz R, Steendijk P, van der Velde ET, van Bel F, Baan J 1991 The end-systolic pressure volume relationship in the newborn lamb: effects of loading and inotropic interventions. Pediatr Res 29:473-482

15. Nakamoto T, Cheng CP, Santamore WP 1989 Estimating left ventricular elastance from one beat in a conscious animal. Circulation 80(suppl II): 151 (abstr)

16. Takeuchi $M$, Igarashi $Y$, Tomimoto $S$, Odake $M$, Hayashi $T$, Tsukamoto $T$ Hata K, Takaoka H, Fukuzaki H 1991 Single-beat estimation of the slope of the end-systolic pressure-volume relation in the human left ventricle. Circulation 83:202-212

17. Kirkpatrick SE, Covell JW, Friedman WF 1973 A new technique for the continuous assessment of fetal and neonatal cardiac performance. Am J Obstet Gynecol 116:963-972

18. Anderson PAW 1992 Physiology of the fetal, neonatal and adult heart. In Polin RA, Fox WW (eds) Fetal and Neonatal Physiology. WB Saunders Company, Philadelphia, pp 722-758

19. Teplinsky K, O'Toole M, Olman M, Walley KR, Wood LDH 1990 Effect of lactic acidosis on canine hemodynamics and left ventricular function. Am J Physiol 27:H1193-H1199

20. Walley KR, Louis TH, Wood LDH 1990 Acute respiratory acidosis decreases left ventricular contractility but increases cardiac output in dogs. Circ Res 67:628-635

21. Morrow RJ, Adamson SL, Bull SB, Ritchie JWK 1989 Effect of placental embolization on the umbilical arterial velocity waveform in fetal sheep. Am J Obstet Gynecol 161:1055-1060

22. Fisher DJ 1986 Acidemia reduces cardiac output and left ventricular contractility in conscious lambs. J Develop Physiol 8:23-31

23. Cromwell TH, Stevens WC, Eger EI 1971 The cardiovascular effects of com pound 469 (Forane) during spontaneous ventilation and $\mathrm{CO}_{2}$ challenge in man. Anesthesiology 35:17-25

24. Biehl DR, Yarnell R, Wade JG, Sitar D 1983 The uptake of isoflurane by the foetal lamb in utero: effect on regional blood flow. Can Anaesth Soc J 30:581-586

25. Cohn HE, Sacks EJ, Heyman MA, Rudolph AM 1974 Cardiovascular re sponses to hypoxemia and acidemia in fetal lambs. Am J Obstet Gynecol 120:817-824

26. Block BS, Schlafer DH, Wentworth RA, Kreitzer LA, Nathanielsz PW 1990 Intrauterine asphyxia and the breakdown of physiologic circulatory compensation in fetal sheep. Am J Obstet Gynecol 162:1325-1331

27. Rudolph AM 1984 The fetal circulation and its response to stress. J Dev Physiol 6:11-19

28. Walker AM, Cannata JP, Dowling MH, Ritchie BC, Maloney JE 1979 Agedependent pattern of autonomic heart rate control during hypoxia in fetal and newborn lambs. Biol Neonate 35:198-208 